\title{
Causas de condenação de carcaças de Gallus gallus domesticus em abatedouros frigoríficos sob Inspeção Federal no Nordeste do Brasil
}

\author{
[Causes of condemnation of carcasses of Gallus gallus domesticus in slaughterhouse under Federal \\ Inspection in the Northeast of Brazil
}

\section{"Artigo Científico/Scientific Article"}

\author{
Tássio José de Oliveira Almeida ${ }^{1}$, Anamélia Sales de Assis ${ }^{1}$, Marcelo Mendonça ${ }^{1}$, \\ Maria Betânia de Queiroz Rolim ${ }^{2 *}$
}

\begin{abstract}
${ }^{1}$ Unidade Acadêmica de Garanhuns, Universidade Federal Rural de Pernambuco, Garanhuns-PE, Brasil.
${ }^{2}$ Departamento de Medicina Veterinária, Universidade Federal Rural de Pernambuco, Recife-PE, Brasil.

*Autor para correspondência/Corresponding author: E-mail: mbveterinaria@yahoo.com.br
\end{abstract}

\section{Resumo}

O estudo teve como objetivo analisar os registros das principais causas de condenação de Gallus gallus domesticus em abatedouros frigoríficos registrados no Serviço de Inspeção Federal, na região Nordeste do Brasil. Foram analisados os registros de abate e de condenação post mortem de carcaças, por meio de levantamento de dados do Sistema de Informações Gerenciais do Serviços de Inspeção Federal - SIGSIF. Os dados foram tabulados e analisados por meio de estatística descritiva, quanto as frequências absoluta e relativa. Nos estados da Bahia, Paraíba e Pernambuco foram abatidas 113.533.032 aves, da espécie Gallus gallus domesticus. Desse total, foram registradas $4,37 \%$ (4.959.238) de condenações de carcaças, das quais 3,71\% (4.214.289) de condenações parciais e $0,66 \%$ (744.949) de condenações totais. As duas principais causas de condenação foram de origem não patológica: contusão, registrada em 54,05\% (2.680.381) das carcaças condenadas e contaminação, com 14,41\% (714.715) dos registros. No entanto, outras causas não patológicas estiveram inclusas nos principais registros de condenação: $2,69 \%$ (133.163) aspecto repugnante/corpos ou causas repugnantes; $0,96 \%$ (47.850) escaldagem excessiva e $0,57 \%$ (28.265) carnes sanguinolentas. As principais condenações de origem patológica foram: 7,93\% (392.992) celulite; 4,17\% (206.997) aerossaculite; 3,90\% (193.436) colibacilose; 3,84\% (190.256) artrite; 2,14\% (106.329) dermatose; $1,62 \%$ (80.404) ascite/síndrome ascítica; $1,45 \%$ (71.979) caquexia e 1,25\% (62.222) miopatia dorsal cranial. A maioria das condenações de carcaças foram de origem não patológica, quando o principal destino foi a condenação parcial. Por outro lado, as alterações de origem patológica foram as principais responsáveis pelas condenações totais de carcaça.

Palavras-Chave: avicultura; contusões; inspeção de carnes.

\begin{abstract}
The goal of this work was to evaluate records for condemnation of chickens (Gallus gallus domesticus) in slaughterhouses registered under the Federal Inspection Service in the northeast of Brazil. Data from the records of slaughter and postmortem condemnation of carcasses were collected and analyzed from the System of Management Information of the Federal Inspection Services - SIGSIF. The data were tabulated and analyzed using descriptive statistics: the absolute and relative frequencies. In the states of Bahia, Paraíba, and Pernambuco, a total of 113,533,032 Gallus gallus domesticus were slaughtered. Of this total, $4.37 \%(4,959,238)$ of whole carcass condemnations were registered, followed by $3.71 \%(4,214,289)$ of partial condemnation, and $0.66 \%(744,949)$ of total condemnation. The two main causes of condemnation are of non-pathological origin: contusion, recorded in $54.05 \%(2,680,381)$ of carcasses condemned, and contamination listed in $14.41 \%(714,715)$. However, other nonpathological causes are included in major condemnation records, such as: repugnant aspect or repugnant causes with $2.69 \%(133,163) ; 0.96 \%(47,850)$ excessive scalding; and $0.57 \%(28,265)$ bloody meats. The main condemnations of pathological origin were: $7.93 \%(392,992)$ cellulite; 4.17\% (206,997) airsacculitis; 3.90\% (193,436) colibacillosis; 3.84\% (190,256) arthritis; $2.14 \%(106,329)$ dermatitis; $1.62 \%(80,404)$ ascites/ascites syndrome; $1.45 \%(71,979)$ cachexia; and $1.25 \%(62,222)$ cranial dorsal myopathy. The most carcass condemnations were nonpathological in origin when the main destination was the partial condemnation. On the other hand, changes of pathological origin were the main cause of whole carcass condemnations.
\end{abstract}

Keywords: poultry farming; bruises; meat inspection.

Recebido em: 25 de agosto de 2017.

Aceito em: 27 de janeiro de 2018 . 


\section{Introdução}

O Serviço de Inspeção Federal - SIF, do Ministério da Agricultura, Pecuária e Abastecimento - MAPA do Brasil, é responsável por assegurar a qualidade de produtos de origem animal (POA), comestíveis e não comestíveis, destinados ao mercado interno e externo, bem como de produtos importados. Em estabelecimentos cárneos, apresenta importante papel fiscalizador, e é o responsável por decisões sanitárias que permeiam em aprovações ou condenações de carcaças (BRASIL, 2017a; 2017b).

As condenações de carcaças nos abatedouros frigoríficos de aves, registrados no SIF, decorrem de enfermidades ou alterações não patológicas que determinam características prejudiciais à qualidade e inocuidade da carne de aves e, muitas vezes, comprometem sua apresentação e valor comercial.

Neste contexto, a inspeção de aves é baseada nas recomendações do Regulamento da Inspeção Industrial e Sanitária de Produtos de Origem Animal - RIISPOA (BRASIL, 2017a) e da Portaria $\mathrm{n}^{\circ} 210$, de 10 de novembro de 1998 (BRASIL, 1998), ambas do MAPA. A inspeção post mortem acontece em três etapas: Linha A, quando é realizado o exame da cavidade celomática; Linha $\mathrm{B}$, exame das vísceras; e Linha $\mathrm{C}$, exame externo da carcaça.

Estudos sobre as causas de condenação de carcaças de Gallus gallus domesticus, espécie de ave doméstica das categorias frango, galeto, galinha e galo, foram realizados em diferentes regiões brasileiras (BRASIL, 1998; Oliveira et al., 2016), principalmente em estabelecimentos cárneos do Centro-Oeste (Santana et al., 2008); Sudeste (Moretti et al., 2010; Gundim et al., 2015; Ebling e Basurco, 2016) e Sul (Ferreira et al., 2012; Paschoal et al., 2012; Ebling e Basurco, 2016; Paiva e Freitas, 2016). No Nordeste, pesquisas ocorreram na Bahia (Lima et al., 2014) e Piaú (Souza et al., 2016), o que mostra a necessidade de mais estudos para a avaliação da cadeia produtiva e as técnicas de abate nos estabelecimentos da região.

O estudo teve como objetivo analisar os registros das principais causas de condenação de Gallus gallus domesticus em abatedouros frigoríficos registrados no Serviço de Inspeção Federal, na região Nordeste do Brasil.

\section{Material e Métodos}

Foi realizado um levantamento de dados disponíveis no Sistema de Informações Gerenciais do Serviço de Inspeção Federal - SIGSIF, na página eletrônica do Serviço de Inspeção Federal SIF (BRASIL, 2017b), relativos ao ano de 2016. Foram analisados os registros de abate de Gallus gallus domesticus em estabelecimentos registrados no SIF, dos estados da Bahia, Paraíba e Pernambuco, pertencentes ao Nordeste do Brasil, assim como a frequência, causas e formas de condenação post mortem de carcaça.

Os diagnósticos incompatíveis com a espécie foram considerados registros inconsistentes. Estes registros foram calculados e, na análise das informações, desconsiderados. Paralelamente, não foi constatada a existência de abatedouro frigorífico de Gallus gallus domesticus sob Inspeção Federal em Alagoas, Ceará, Maranhão, Rio Grande do Norte e Sergipe. No estado do Piauí, entretanto, apesar de constar no sistema a instalação do referido estabelecimento cárneo, no período de estudo não houve registros de condenação de carcaça.

Os dados foram tabulados e analisados por meio de estatística descritiva, quanto às frequências absoluta e relativa, em relação ao total de condenações de carcaça e o número de aves abatidas neste período. As condenações foram classificadas como causas de condenação de origem patológica ou não patológica.

\section{Resultados e Discussão}

No ano de 2016 foram abatidas mais de 113,53 milhões de aves da espécie Gallus gallus domesticus, em abatedouros frigoríficos registrados no Serviço de Inspeção Federal, pertencentes aos estados da Bahia, Paraíba e Pernambuco, da região Nordeste (Tabela 1). Destas, $88,0 \%$ (99.909.595) eram frangos; $11,75 \%$ (13.335.349) galetos; $0,23 \%$ (263.486) galinhas; e $0,02 \%$ (24.602) galos.

Os principais registros de abate corresponderam aos estados de Pernambuco e Bahia, o que está relacionado ao número de abatedouros frigoríficos registrados no Serviço de Inspeção Federal. Em Pernambuco havia cinco abatedouros, localizados nos municípios de Belo Jardim, Nazaré da Mata, Paulista, Pesqueira e São José do Egito; na Bahia havia três, em Feira de 
Santana, Luís Eduardo Magalhães e São Gonçalo dos Campos; enquanto na Paraíba, um estabelecimento em Guarabira, o que justifica a menor frequência de abate.

Os registros de condenação contabilizaram 4.959.258 carcaças, dos quais 20 foram inconsistentes, o que representou $0,0004 \%$ do total de registros. Enquanto os registros consistentes de condenação contabilizaram 4.959.238 carcaças. Dessa forma, a frequência de condenação, em relação ao total de abates foi de $4,37 \%$.

O resultado foi próximo ao estudo de Paiva e Freitas (2016), que identificaram uma frequência de $4,15 \%$ de condenação de carcaças de frangos, em abatedouro registrado no SIF, no estado do Paraná. Entretanto, foi superior aos 2,74\% em estudo realizado em abatedouros frigoríficos dos estados do Paraná, Santa Catarina, Rio Grande do Sul e São Paulo (Ebling e Basurco, 2016). Por outro lado, inferior aos $5,12 \%$ em estabelecimento do Rio Grande do Sul (Ferreira et al., 2012); aos $8,06 \%$ em abatedouro do Noroeste do Paraná, destinado exclusivamente ao mercado interno (Paschoal et al., 2012) e aos 8,3\% em dois estabelecimentos do estado de Goiás (Santana et al., 2008).
A frequência de condenação de carcaças de Gallus gallus domesticus foi relativamente semelhante para os estados trabalhados no presente estudo. A maior frequência correspondeu aos registros da Paraíba $(4,74 \%)$, Bahia $(4,34 \%)$ e, por fim, Pernambuco $(4,24 \%)$.

As formas de condenação contabilizaram valores expressivamente distintos, uma vez que as condenações parciais ocorreram em $3,71 \%$ das aves abatidas (Tabela 1), o que corresponde a $84,98 \%$ do total de condenações. Nestas, a parte afetada da carcaça é removida e o restante liberado e destinado para sala de cortes. Em contrapartida, as condenações totais, quando toda a carcaça é rejeitada, ocorreram em $0,66 \%$, e representou $15,02 \%$ das condenações. O resultado foi semelhante ao de algumas pesquisas, as quais constataram que, do total de aves abatidas, 2,40\% no Paraná, Santa Catarina, Rio Grande do Sul e São Paulo (Ebling e Basurco, 2016); 4,03\% no Paraná (Paiva e Freitas, 2016); e 4,74\%, no Rio Grande do Sul (Ferreira et al., 2012), tiveram suas carcaças condenadas parcialmente, enquanto as condenações totais ocorreram em, respectivamente, $0,34 \% ; 0,15 \%$; e $0,65 \%$ das aves abatidas.

Tabela 1. Condenações parciais e totais de carcaças de Gallus gallus domesticus em abatedouros frigoríficos sob Inspeção Federal no Nordeste do Brasil, em 2016.

\begin{tabular}{lcccccccc}
\hline \multirow{2}{*}{ Estado } & Aves abatidas & \multicolumn{2}{c}{ Condenação parcial } & \multicolumn{2}{c}{ Condenação total } & \multicolumn{3}{c}{ Total } \\
\cline { 3 - 9 } & & FA* $^{*}$ & FCA $^{* *}$ & FA & FCA & FA & FR*** & FCA \\
\hline Pernambuco & 52.499 .498 & 1.899 .713 & 3,62 & 327.645 & 0,62 & 2.227 .358 & 44,91 & 4,24 \\
Bahia & 40.363 .851 & 1.401 .330 & 3,47 & 351.585 & 0,87 & 1.752 .915 & 35,35 & 4,34 \\
Paraíba & 20.669 .683 & 913.246 & 4,42 & 65.719 & 0,32 & 978.965 & 19,74 & 4,74 \\
\hline Total & $\mathbf{1 1 3 . 5 3 3 . 0 3 2}$ & $\mathbf{4 . 2 1 4 . 2 8 9}$ & $\mathbf{3 , 7 1}$ & $\mathbf{7 4 4 . 9 4 9}$ & $\mathbf{0 , 6 6}$ & $\mathbf{4 . 9 5 9 . 2 3 8}$ & $\mathbf{1 0 0}$ & $\mathbf{4 , 3 7}$
\end{tabular}

*FA=Frequência Absoluta; **FCA=Frequência de Condenação em Relação ao Total de Abates; ***FR=Frequência Relativa. Fonte: adaptado do SIGSIF (BRASIL, 2017b)

Conjuntamente, as principais causas de condenação de carcaças de Gallus gallus domesticus foram registradas em $98,9 \%$ do total de condenações. Destas, $72,68 \%$ relativas as causas não patológicas, responsáveis pela condenação de carcaça em 3,17\% dos abates (Tabela 2). Estas alterações estão relacionadas às inadequações no manejo pré-abate e/ou de abate, o que revela a necessidade de adequação das técnicas e equipamentos de abate e capacitação dos colaboradores, para que possam manejar as aves de forma a garantir o bem estar animal, desde a apanha na granja, transporte e pendura. Ainda, capacitá-los sobre a implicação das etapas de abate e da regulagem dos equipamentos sobre a qualidade final dos produtos (Gundim et al., 2015; Ebling e Basurco, 2016).

As alterações de origem patológica representaram $26,31 \%$ dos registros de condenação de carcaças, o que ocasionou o descarte de $1,15 \%$ das carcaças de aves abatidas. Estas condenações refletem a existência de falhas no setor produtivo, sejam elas sanitárias ou de manejo. Dessa forma, aponta a necessidade de intensificação das medidas de biosseguridade e adequação do manejo produtivo, para resolução do quadro e prevenção das enfermidades (Oliveira et al., 2016).

A principal causa de condenação de carcaças, em abatedouros avícolas sob Inspeção Federal, na região Nordeste, foi a contusão, 
registrada em mais da metade das condenações $(54,05 \%)$, com ocorrência em $2,36 \%$ das aves abatidas (Tabela 2). O resultado foi superior aos $1,57 \%$ de condenação, verificados por Oliveira et al. (2016), quando a lesão ficou como a segunda mais frequente em estabelecimentos brasileiros registrados no SIF e representou $26,1 \%$ do total de condenações. A alteração está relacionada ao manejo pré-abate que, quando inadequado, proporciona a ocorrência de fraturas, contusões, rompimentos de pele e hematomas, especialmente nas pernas, asas e peito. Segundo Moretti et al. (2010), podem estar envolvidas as etapas de apanha; carregamento; transporte; recepção; manejo de retirar a ave da gaiola; e sua pendura na nória, para seguir o fluxo normal de abate.

As carcaças de animais que apresentem contusão generalizada ou múltiplas fraturas devem ser condenadas totalmente. Entretanto, as lesões traumáticas quando localizadas, implicam apenas na rejeição da parte atingida, enquanto as lesões extensas, mas sem comprometimento total, possibilitam o aproveitamento condicional da peça (BRASIL, 2017a).

As contusões localizadas foram mais frequentes, uma vez que a rejeição parcial contabilizou 2.635.329 carcaças, o que representou $62,53 \%$ do total de 4.214 .289 condenações parciais identificadas no presente estudo. Outras pesquisas apontam as contusões/fraturas como a principal causa de condenação de carcaças, responsável por $65,26 \%$ (Lima et al., 2014) e 54,38\% (Paschoal et al., 2012) do total de condenações parciais e, respectivamente, $2,48 \%$ e $4,29 \%$ das aves abatidas eram condenadas pela alteração. Este fato revela que, nos estabelecimentos destes estudados, o manejo pré-abate era ainda mais precário e inadequado em relação ao presente estudo.

A contaminação foi registrada como causa de condenação de carcaças em $0,63 \%$ dos abates, o que representou $14,41 \%$ das condenações. Assim, foi a segunda principal causa de condenação, neste estudo (Tabela 2). O resultado foi superior aos achados de Oliveira et al. (2016), que trabalharam com os dados do SIGSIF de 2006 a 2011 e verificaram frequência de $0,16 \%$ de registros de condenação por contaminação em abatedouros frigoríficos sob Inspeção Federal. A alteração pode ocorrer por diferentes causas, entretanto, a ruptura intestinal é a principal e ocorre, principalmente, quando as aves não recebem um manejo pré-abate adequado, com um período mínimo de 6 a 8 horas de jejum (BRASIL, 1998).
As carcaças, partes de carcaça e órgãos que apresentem áreas de contaminação por conteúdo gastrintestinal, urina, leite, bile, pus ou de qualquer outra natureza devem ser condenados, caso não seja possível a remoção completa da área contaminada (BRASIL, 2017a). No presente estudo, a maioria das condenações por contaminação foram parciais $(89,70 \%)$, o que contabilizou 641.081 carcaças. O resultado mostra que a alteração ocorreu, principalmente, de forma localizada, o que permitiu o toalete da carcaça, para rejeição da região contaminada.

A celulite foi a terceira principal causa de condenação de carcaças neste estudo. No entanto, foi a principal causa de origem patológica, registrada em $0,35 \%$ das aves abatidas, o que representou $7,93 \%$ do total de condenações (Tabela 2 ). Resultados superiores, de $0,76 \%$ e $1,08 \%$, em relação ao total de abates, foram relatados, respectivamente, por Lima et al. (2014) e Paschoal et al. (2012). A lesão é uma inflamação purulenta, de etiologia multifatorial, aguda e difusa do tecido subcutâneo, que normalmente acomete a região ventral do abdômen e sobrecoxa (Leclerc et al., 2003). A colibacilose, estafilococose e falhas no manejo sanitário são as principais causas desta lesão (Andreatti Filho, 2006).

Os processos inflamatórios, tais como a aerossaculite, coligranulomatose, dermatose, pericardite, enterite, ooforite, hepatite, síndrome ascítica, miopatias e discondroplasia tibial, determinam a condenação parcial da carcaça, quando restritas, ou total, caso apresente lesão extensa, múltipla ou evidência de caráter sistêmico (BRASIL, 1998; 2017a). No caso da celulite, no atual estudo, a grande maioria das carcaças apresentaram lesões restritas, uma vez que foram registradas 392.506 condenações parciais de carcaça, o que representou a quase totalidade $(99,88 \%)$ das formas de condenação pela causa (Tabela 2).

Neste estudo, a aerossaculite foi registrada como causa de descarte de $0,18 \%$ das carcaças. Este resultado foi semelhante aos $0,16 \%$ de carcaças condenadas por aerossaculite, segundo Oliveira et al. (2016), mas superiores aos 0,009\% do total de condenação de aves em estabelecimentos do Paraná (Paschoal et al., 2012). Esta alteração patológica foi a quarta principal causa de condenação, no atual estudo, entretanto, foi a principal causa de condenação total de carcaça, uma vez que foi contabilizada 159.287 carcaças, o que representou $76,95 \%$ das formas de 
condenação pela lesão e, ainda, $21,38 \%$ das condenações totais. Assim, na maioria das carcaças condenadas houve o envolvimento extensivo dos sacos aéreos ou evidências de caráter sistêmico, o que ocasiona rejeição total (BRASIL, 1998).

Ainda sobre as causas de origem patológica, a colibacilose foi registrada como causa de condenação de $0,17 \%$ das carcaças de aves abatidas, o que representou $3,90 \%$ do total de condenações. A alteração foi a segunda principal causa no ranking de condenação total, com 146.587 registros, o que representou $19,68 \%$ das condenações totais. Por outro lado, em $0,16 \%$ das aves abatidas, foram registradas condenações de carcaça por artrite, o que representou $3,84 \%$ das condenações, um resultado próximo aos $0,32 \%$ (Santana et al., 2008), verificados em relação ao total de abates.

Dos registros de condenação de carcaças no Nordeste, $0,12 \%$ foram relativas ao aspecto repugnante e corpos ou causas repugnantes. As duas causas estão relacionadas a situações que proporcionem o aspecto repugnante da carcaça, dessa forma, é cabível a análise conjunta. O resultado se assemelha aos $0,126 \%$, de aspecto repugnante, no Rio Grande do Sul (Ferreira et al., 2012) e 0,17\% na Bahia (Lima et al., 2014). Outro estudo aponta resultado inferior de 0,079\% (Paschoal et al., 2012). Várias situações podem desencadear $o$ aspecto repugnante, quando determinadas características na carcaça causam repúdio ao consumidor, no momento de sua comercialização. No entanto, o estresse é o principal fator, que decorre de inadequações em determinadas etapas, desde o manejo pré-abate, que ocasionam duas alterações conhecidas como carne DFD (Dark, Firm and Dry - escura, firme e seca) e PSE (Pale, Soft and Exsudative - pálida, mole e exsudativa), relacionadas, respectivamente, ao estresse crônico e agudo pré-abate (Shiraishi et al., 2013).

Dermatose é um termo utilizado pelo serviço de inspeção como uma denominação para as doenças de pele, com exceção da celulite (Oliveira et al., 2016). A alteração foi registrada como causa de condenação de 0,09\% das carcaças de aves abatidas, no presente estudo, relativamente próximo aos 0,02\% na Bahia (Lima et al., 2014). Enquanto a ascite/síndrome ascítica, ocorreu em $0,07 \%$ das aves abatidas, próximo aos $0,03 \%$, no estudo anteriormente citado. Esta lesão é uma condição patológica multifatorial, com acúmulo de líquido na cavidade abdominal, o que gera, especialmente, a rejeição total. Assim, as condenações totais contabilizaram 76.050, o que representou $94,58 \%$ das formas de condenações pela causa, no atual estudo.

A caquexia foi registrada como causa de condenação total das carcaças em $0,06 \%$ das aves abatidas no Nordeste, em 2016. Estudos realizados no Brasil constataram resultados com percentuais relativamente baixos: $0,17 \%$ (Ferreira et al., 2012) e $0,026 \%$ (Paschoal et al., 2012). A legislação brasileira regulamenta que as aves caquéticas devem ter condenação total, sendo inapropriadas ao consumo humano (BRASIL, 2017a). Para a miopatia dorsal cranial, uma lesão muscular que acomete, sobretudo, machos de linhagens pesadas com as maiores médias de peso e idade de abate (Zimermann et al., 2011), a condenação de carcaças ocorreu em $0,05 \%$ das aves abatidas. Este resultado foi relativamente próximo aos $0,01 \%$ no Rio Grande do Sul (Roso e Dickel, 2011).

A escaldagem excessiva decorre, especialmente, de paradas na linha de abate, por queda de energia, quando as aves ficam submersas no tanque de escaldagem por tempo prolongado (Maschio e Raszl, 2012). No atual estudo, foi registrada como causa de condenação de carcaças em $0,04 \%$ das aves abatidas, semelhante a outras avaliações em estados do Nordeste: 0,04\% (Lima et al., 2014) e $0,12 \%$ (Souza et al., 2016). Este processo determina a ocorrência de lesões mecânicas extensas, quando a carcaça deve ser condenada totalmente (BRASIL, 1998). Entretanto, quase metade das condenações foram parciais, o que decorre de lesões não extensas.

A ocorrência de carnes sanguinolentas, que decorre de falhas no processo de sangria, alteração também conhecida como má sangria, foi registrada em $0,02 \%$ das aves abatidas, nesta pesquisa. $\mathrm{O}$ resultado foi semelhante a estudos realizados no Paraná, de 0,04\% (Paschoal et al., 2012) e em Goiás, de $0,02 \%$ (Santana et al., 2008). No entanto, a maioria das pesquisas mostra resultados superiores: 0,24\% (Souza et al., 2016), 0,09\% (Lima et al., 2014) e 0,08\%. Este último, em outro estabelecimento de Goiás (Santana et al., 2008).

As demais causas de condenação de carcaças (Tabela 2) foram alterações registradas em baixa frequência e, em conjunto, representaram $1,1 \%$ das condenações no período de estudo: evisceração 
retardada, com 18.852 carcaças condenadas; miopatia (15.931); abscesso (11.917); síndrome hemorrágica (2.303); miocardite (540); doença de
Marek (518); salpingite (105); coligranulomatose (60); neoplasia (14); septicemia (5) e candidíase (4).

Tabela 2. Causas de condenação de carcaças de Gallus gallus domesticus em abatedouros frigoríficos sob Inspeção Federal no Nordeste do Brasil, em 2016.

\begin{tabular}{|c|c|c|c|c|c|}
\hline \multirow[t]{2}{*}{ Causas de condenação } & \multirow{2}{*}{$\begin{array}{c}\text { Condenação } \\
\text { parcial }\end{array}$} & \multirow{2}{*}{$\begin{array}{c}\text { Condenação } \\
\text { total }\end{array}$} & \multicolumn{3}{|c|}{ Total } \\
\hline & & & FA* & FR** & $\mathbf{F C A} * * *$ \\
\hline \multicolumn{6}{|l|}{ Principais causas não patológicas } \\
\hline Contusão & 2.635 .329 & 45.052 & 2.680 .381 & 54,05 & 2,36 \\
\hline Contaminação & 641.081 & 73.634 & 714.715 & 14,41 & 0,63 \\
\hline $\begin{array}{l}\text { Aspecto repugnante/corpos ou causas } \\
\text { repugnantes }\end{array}$ & 36.601 & 96.562 & 133.163 & 2,69 & 0,12 \\
\hline Escaldagem excessiva & 22.151 & 25.699 & 47.850 & 0,96 & 0,04 \\
\hline Carnes sanguinolentas & 3.398 & 24.867 & 28.265 & 0,57 & 0,02 \\
\hline Subtotal & 3.338 .560 & 265.814 & 3.604 .374 & 72,68 & 3,17 \\
\hline \multicolumn{6}{|l|}{ Principais causas patológicas } \\
\hline Celulite & 392.506 & 486 & 392.992 & 7,93 & 0,35 \\
\hline Aerossaculite & 47.710 & 159.287 & 206.997 & 4,17 & 0,18 \\
\hline Colibacilose & 46.849 & 146.587 & 193.436 & 3,90 & 0,17 \\
\hline Artrite & 189.333 & 923 & 190.256 & 3,84 & 0,16 \\
\hline Dermatose & 105.381 & 948 & 106.329 & 2,14 & 0,09 \\
\hline Ascite/síndrome ascítica & 4.354 & 76.050 & 80.404 & 1,62 & 0,07 \\
\hline Caquexia & - & 71.979 & 71.979 & 1,45 & 0,06 \\
\hline Miopatia dorsal cranial & 58.800 & 3.422 & 62.222 & 1,25 & 0,05 \\
\hline Subtotal & 844.933 & 459.682 & 1.304 .615 & 26,31 & 1,15 \\
\hline \multicolumn{6}{|l|}{ Demais causas } \\
\hline Subtotal & 30.796 & 19.453 & 50.249 & 1,01 & 0,04 \\
\hline Total & 4.214.289 & 744.949 & 4.959 .238 & 100 & 4,37 \\
\hline
\end{tabular}

*FA=Frequência Absoluta; **FR=Frequência Relativa; ***FCA=Frequência de Condenação em Relação ao Total de Abates. Fonte: adaptado do SIGSIF (BRASIL, 2017b)

\section{Conclusão}

A maioria das condenações de carcaças de Gallus gallus domesticus, registradas em abatedouros frigoríficos sob Inspeção Federal nos estados da Bahia, Paraíba e Pernambuco, localizados no Nordeste do Brasil, são de origem não patológica (contusão, contaminação, aspecto repugnante/corpos ou causas repugnantes, escaldagem excessiva e carnes sanguinolentas), quando o principal destino é a condenação parcial. Por outro lado, as alterações de origem patológica (celulite, aerossaculite, colibacilose, artrite, dermatose, caquexia, miopatia dorsal cranial e ascite/síndrome ascítica) são as principais responsáveis pelas condenações totais de carcaça.

Outras alterações ocasionaram menos perdas de carcaças por condenação (miopatia, abscesso, síndrome hemorrágica, miocardite, doença de Marek, salpingite, coligranulomatose, neoplasia, septicemia e candidíase). Mas sua abordagem é importante, pois permite comparar os resultados aos de pesquisas semelhantes, além de alertar o setor produtivo frente às devidas precauções de manejo e biosseguridade, no intuito de evitar volumes preocupantes de condenação e, consequentemente, prejuízos econômicos.

\section{Referências}

Andreatti Filho, R.L. Saúde aviária e doenças. São Paulo: Roca, 2006, 314p.

BRASIL. Ministério da Agricultura e Abastecimento.

Regulamento Técnico da Inspeção Tecnológica e Higiênico-Sanitária de Carne de Aves. Portaria ${ }^{\circ} 210$ de 10 de novembro de 1998. Brasília - DF, Diário Oficial da União, 227, Seção I, 1998. Disponível em: <http://www.cidasc.sc.gov.br/inspecao/files/20 12/08/port-210.pdf >. Acesso em: 24 ago. 2017.

BRASIL. Ministério da Agricultura, Pecuária e Abastecimento. Regulamento da Inspeção Industrial e Sanitária de Produtos de Origem Animal - RIISPOA. Decreto n ${ }^{\circ} 9.013$, de 29 de março de 2017; regulamenta a Lei ${ }^{\circ} 1.283$, de 
18 de dezembro de 1950 e a Lei $n^{\circ} 7.889$, de 23 de novembro de 1989. Brasília, 2017a. Disponível em: $<$ https://edisciplinas.usp.br/pluginfile.php/3198 817/mod_resource/content/1/DECRETON\%C2\%BA-9.013-DE-29-DEMAR\%C3\%87O-DE-2017_RIISPOA.pdf>. Acesso em: 24 ago. 2017.

BRASIL. Ministério da Agricultura, Pecuária e Abastecimento. Serviço de Inspeção Federal. 2017b. Disponível em: $<$ http://www.agricultura.gov.br/assuntos/inspec ao/produtos-animal/sif $>$. Acesso em: 23 ago. 2017.

Ebling, P.D.; Basurco, V. Análise das perdas econômicas oriundas da condenação de carcaças nos principais estados brasileiros produtores de frangos de corte. Ciências Agroveterinárias e Alimentos, 1(1): 1-11, 2016.

Ferreira, T.Z.; Sesterhenn, R.; Kindlein, L. Perdas econômicas das principais causas de condenações de carcaças de frangos de corte em Matadouros-Frigoríficos sob Inspeção Federal no Rio Grande do Sul, Brasil. Acta Scientiae Veterinariae, 40(1): 1-6, 2012.

Gundim, L.F.; Rodrigues, E.A.; Blanca, W.T.; Coleto, A.F.; Medeiros, A.A. Causas de condenações de frangos de corte relacionadas a manejo e ambiência. Enciclopédia Biosfera, 11(21): 515-522, 2015.

Lima, K.C.; Mascarenhas, M.T.V.L.; Cerqueira, R.B. Técnicas operacionais, bem-estar animal e perdas econômicas no abate de aves. Archives of Veterinary Science, 19(1), 38-45, 2014.

Leclerc, B.; Fairbrother, J.M.; Boulianne, M.; Messier, S. Evaluation of the adhesive capacity of Escherichia coli isolates associated with avian cellulitis. Avian Diseases, 47(1): 21-31, 2003.

Maschio, M.M.; Raszl, S.M. Impacto financeiro das condenações post-mortem parciais e totais em uma empresa de abate de frango. Revista Etech, 1(1): 26-38, 2012.

Moretti, L.D.; Dias, R.A.; Telles, E.O.; Balian, S.C. Time series evaluation of traumatic lesions and airsacculitis at one poultry abattoir in the state of São Paulo, Brazil (1996-2005). Preventive Veterinary Medicine, 94(1): 231-239, 2010.
Oliveira, A.A.; Andrade, M.A.; Armendaris, P.M.; Bueno, P.H.S. Principais causas de condenação ao abate de aves em matadouros frigoríficos registrados no serviço brasileiro de Inspeção Federal entre 2006 e 2011. Ciência Animal Brasileira, 17(1): 79-89, 2016.

Paiva, F.F.; Freitas, E.S. Estudo retrospectivo de principais condenações em frango de corte griller nas linhagens COBB e R0SS 808. Revista Cultivando o Saber, 9: 193-202, 2016.

Paschoal, E.C.; Otutumi, L.K.; Silveira, A.P. Principais causas de condenações no abate de frangos de corte de um abatedouro localizado na região Noroeste do Paraná, Brasil. Arquivos de Ciências Veterinárias e Zoologia da UNIPAR, 15(2): 93-97, 2012.

Roso, K.; Dickel, E. Estudo da prevalência da miopatia dorsal cranial e perdas econômicas ocorridas em um matadouro de aves localizado no norte do estado do Rio Grande do Sul nos meses de abril à novembro de 2010. Revista de Ciências Agroveterinárias, 10(69): 1-3, 2011.

Santana, A.P.; Murata, L.S.; Freitas, C.G.; Delphino, M.K.; Pimente, C.M. Causes of condemnation of carcasses from poultry in slaughterhouses located in State of Goiás, Brazil. Ciência Rural, 38(9): 2587-2592, 2008.

Shiraishi, V.T.I.; Leite, P.A.G.; Nascimento, K.R. Condenações por aspecto repugnante em frangos abatidos sob inspeção estadual, no município de São Gonçalo dos Campos - Bahia, Brasil. Veterinária e Zootecnia, 20(3): 318325, 2013.

Souza, I.J.G.S.; Pinheiro, R.E.E.P.; Rodrigues, A.M.D.; Klein Júnior, M.H.; Peneluc, T. Condenações não patológicas de carcaças de frangos em um matadouro-frigorífico sob inspeção federal no estado do Piauí. Revista Brasileira de Higiene e Sanidade Animal, 10(1): 68-77, 2016.

Zimermann, F.; Fallavena, L.C.B.; Salle, F.O.; Moraes, L.B.; Moraes, H.L.S.; Salle, C.T.P.; Nascimento, V.P. Pesquisa etiológica da miopatia dorsal cranial em frangos de corte. Revista de Educação Continuada em Medicina Veterinária e Zootecnia, 9(3): 6970, 2011. 